\title{
Synthesis of epi-chloranthalactones A, B, D and E
}

Thomas W. Fenlon, Michael W. Jones, Robert M. Adlington and Victor Lee*

Department of Chemistry, University of Oxford, Chemistry Research Laboratory, 12 Mansfield Road, Oxford, OX1 3TA, UK

victor.lee@chem.ox.ac.uk

Click here to insert a dedication

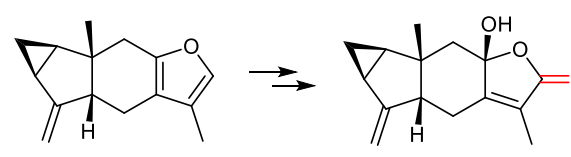

rac-epi-lindenene

epi-chloranthalactone D

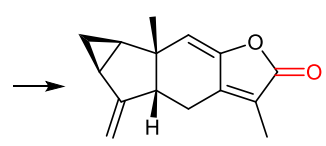

epi-chloranthalactone A<smiles>C=C1C2C[C@H]2[C@]2(C)[C@@H]1CC1=C(C)C(=O)O[C@@]1(O)[C@@H]2O</smiles>

epi-chloranthalactone $\mathrm{E}$

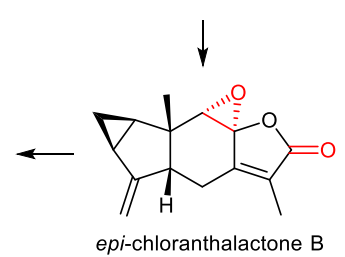

\section{Received:
Accepted:
Published online: \\ Publishec
DOI:}

Abstract The synthesis of various epimers of lindenane class of sesquiterpenes from epi-lindenene, based on a possible biosynthetic hypothesis, is described.

Key words Sesquiterpenes, Chloranthalactones, Aldol reaction, biosynthesis, oxidation.

Chloranthalactones A-E (1-5) are a group of sesquiterpene lactones with a common lindenane skeleton that were first isolated from the aerial and root parts of Chloranthus japonicas and the root of Chloranthus glaber. ${ }^{1}$ These compounds were shown to be moderately cytotoxic against mouse lymphosarcoma L-5178Y cells. Compounds 1-5 are structurally similar to the natural product lindenene (6), which was isolated from the dried root of Lindera strychnifolia Vill. ${ }^{2}$ This plant is a constituent of the Chinese drug T'ien T'ai wu yao. Despite the structural resemblance between lindenene (6) and chloranthalactones A-E (1-5), compound 6 is not found in any species of the Chloranthaceae. Although the chloranthalactones A-E (1-5) and lindenene (6) are not phytochemically related, one can postulate that $\mathbf{6}$ could be a possible biosynthetic precursor of compound 1-5. It is interesting to note that $\mathbf{6}$ was also found in the coral Acanthogorgia vagae. ${ }^{3}$ (Figure 1)

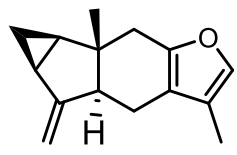

lindenene (6)

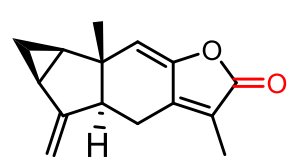

chloranthalactone $\mathrm{A}(\mathbf{1})$

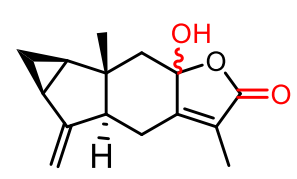

chloranthalactone D (4)

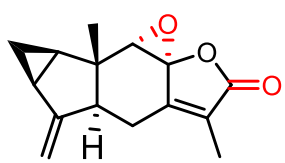

chloranthalactone B (2)

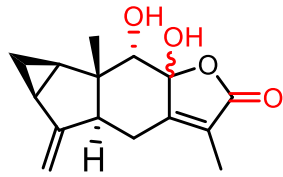

chloranthalactone $\mathrm{E}(\mathbf{5})$

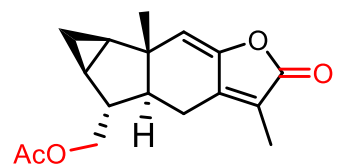

chloranthalactone $\mathrm{C}(3)$ biosynthetic
oxidation

Figure 1 Possible biosynthetic relationship between lindenene (6) and the chloranthalactones A-E

The structural novelty of sesquiterpenes with the lindenane skeletons has posed a challenge to the synthetic organic chemistry community and a number of research groups have reported their synthetic efforts in this area. ${ }^{4}$ We have previously completed the synthesis of rac-lindenene $(6)^{5}$ and would like to explore its possible conversion to various chloranthalactones. Since a supply of rac-epi-lindenene (7) was available in reasonable quantity in our laboratory, we therefore decided to test our biosynthetic hypothesis using it as the starting material. Our original plan was to investigate whether lindenene (6) could be transformed into lindenatriene (8), the putative biosynthetic precursor of the more complex terpene shizukaol A, ${ }^{6}$ via various chloranthalactones as intermediates. However, we realised that epi-lindenene (7) could also be a 
suitable precursor for such purpose as lindenatriene (8) is devoid of the C-5 stereocentre. Herein, we report our effort in the conversion of rac-epi-lindenene (7) to various epichloranthalactones (Figure 2).

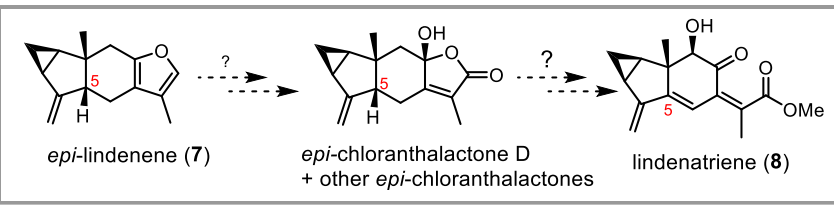

Figure 2 Epi-lindenene (7) as a possible precursor to various chloranthalactones

We envisaged that the butenolide motif in the chloranthalactones could be obtained by oxidation ${ }^{7}$ of the furan ring in lindenene (6) and the same concept was applied to chemically modify epi-lindenene (7). Since the synthesis of 7 still required a considerable amount of effort, the initial investigations were conducted on model compound 11. This compound could easily be prepared in two steps by aldol condensation of 4-tert-butylcyclohexanone with ketone 9 followed by acid catalysed dehydration ${ }^{8}$ of the intermediate product $\mathbf{1 0}$ (Scheme 1).

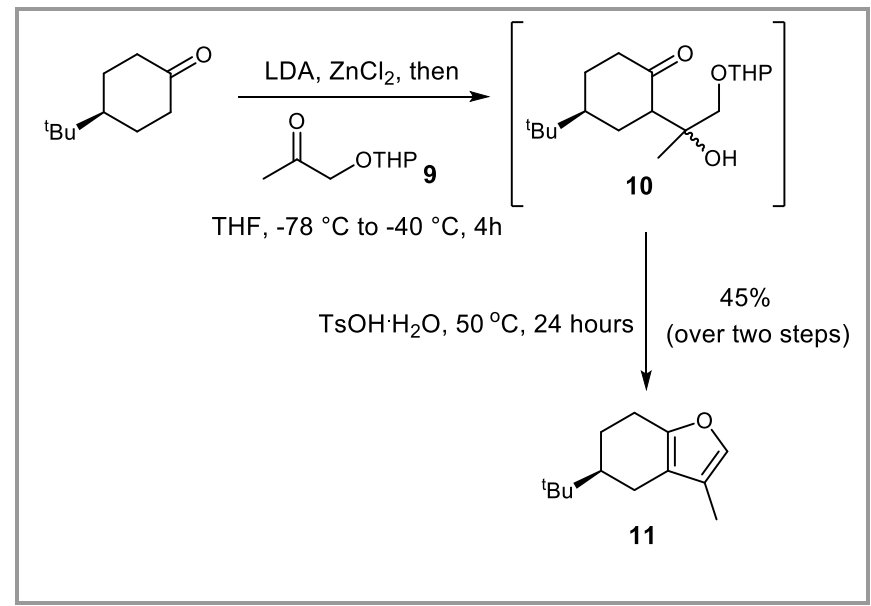

Scheme 1 Synthesis of model compound 11

It is well documented that singlet oxygen oxidation of furan and base induced decomposition of the resultant endo-peroxide is a reliable method for generating the hydroxyfuranone moiety. ${ }^{7}$ However, we found this transformation was not straightforward when it was performed on 11. Initially exposure of $\mathbf{1 1}$ to singlet oxygen and Hünig's base in dichloromethane, ${ }^{9}$ gave a mixture of products. Chromatographic purification of this mixture gave a low yield of the desired hydroxyfuranone $\mathbf{1 2}$ and its dehydrated product 13 (Scheme 2). The stereochemistry of hydroxyfuranone $\mathbf{1 2}$ can be rationalised by the reversible cyclisation of the ketoacid that was formed by the breakdown the endoperoxide intermediate. Therefore $\mathbf{1 2}$ is the thermodynamic product.

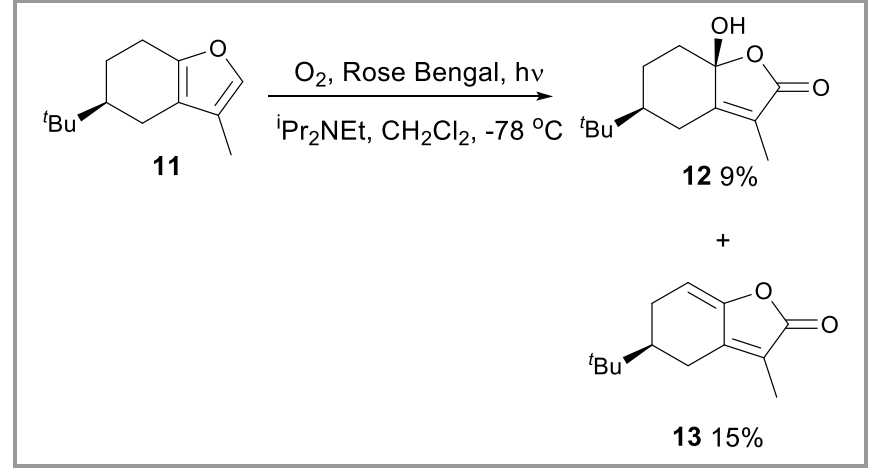

Scheme 2 Initial investigation on the oxidation of 11.

In an attempt to improve this transformation, the same reaction was repeated in methanol. This gave methoxyfuranone $\mathbf{1 4}$ in good yield $(80 \%)$ as the only product. This compound could be hydrolysed by potassium hydroxide to the desired hydroxyfuranone 12 in 77\% yield (Scheme 3).

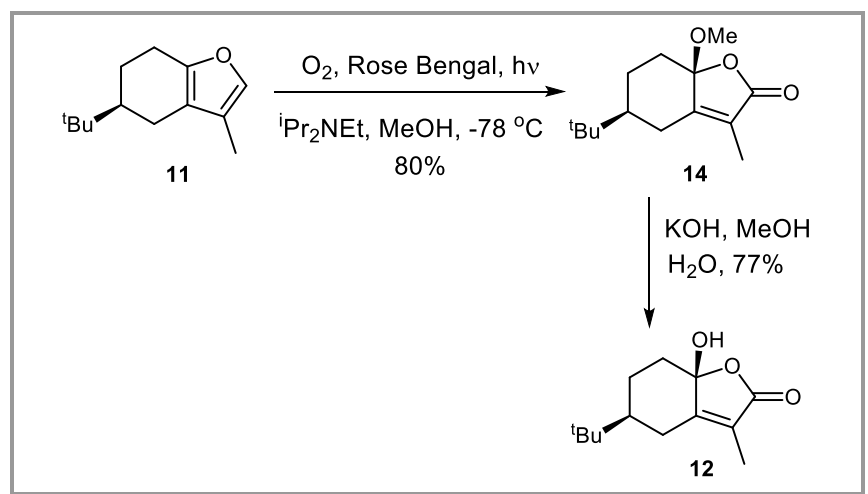

Scheme 3 Oxidation of 11 and hydrolysis of 14 to compound 12 .

Compound 14 was found to be crystalline and its structure was confirmed by X-ray diffraction (Figure 3). ${ }^{10}$

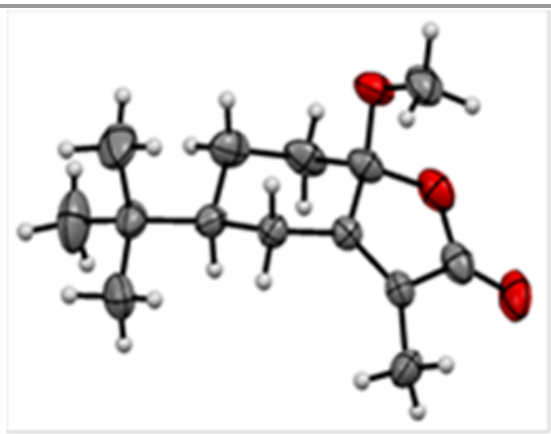

Figure 3 ORTEP representation of compound 14 with thermal ellipsoids at $50 \%$ probability

Interestingly when the oxidation of $\mathbf{1 1}$ was conducted in ethanol or iso-propanol, a mixture of $\mathbf{1 2}$ and the corresponding alkoxyfuranone was obtained.

Despite the relative ease of the transformation from 11 into $\mathbf{1 2}$, the overall yield was only about $62 \%$ over two steps. This 
prompted us to explore other oxidation protocols in the hope of improving the overall yield of $\mathbf{1 2}$. Garst and co-workers previously reported the oxidation of 2-trimethylsilylfuran to the corresponding hydroxyfuranone. ${ }^{11}$ Based on Garst's precedence, 11 was converted to its 2-trimethylsilyl derivative 15. Oxidation of $\mathbf{1 5}$ with singlet oxygen gave 12. The overall yield of 12 was $79 \%$, which was significantly higher than the earlier route. ${ }^{12}$ Clive et al. reported a direct method for the oxidation of furan to hydroxyfuranone using sodium chlorite. ${ }^{13}$ Application of Clive's method to $\mathbf{1 1}$ gave an excellent yield of $\mathbf{1 2}$ as product (Scheme 4)

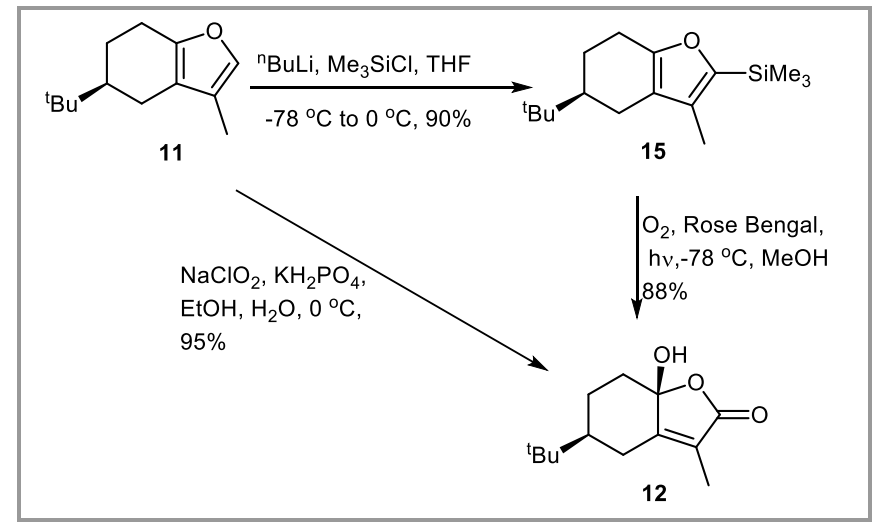

Scheme 4 Synthesis of 12 from 11

Compound 12 was then dehydrated by phosphoryl chloride to enol-ester 13, based on the literature precedent established by Uchida. ${ }^{1} 13$ was then epoxidised using $m$ CPBA to afford compound 16. The acid catalysed hydrolysis of epoxide $\mathbf{1 6}$ gave diol $\mathbf{1 7}$ as product (Scheme 5).

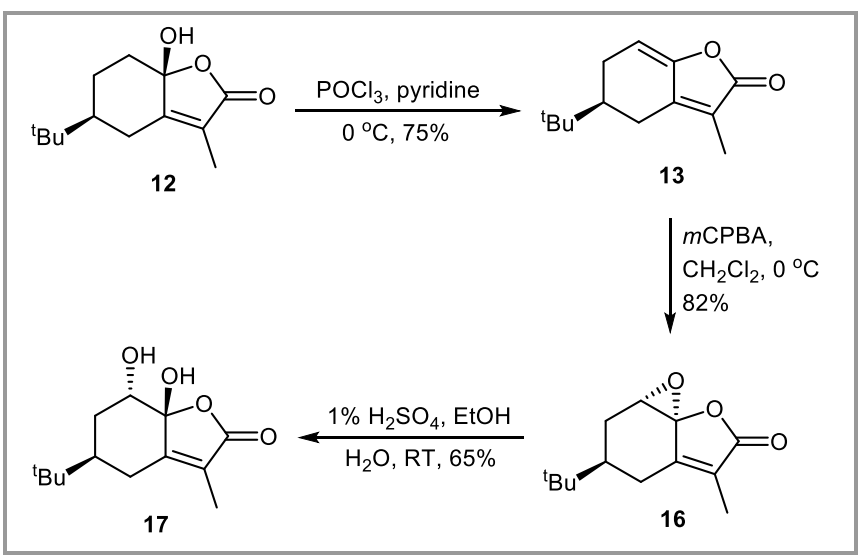

Scheme 5 Chemical modifications of hydroxyfuranone 12 to diol 17.

Both 16 and 17 were crystalline solids and found to be suitable for X-ray diffraction studies. For compound 16, its crystal structure clearly showed the trans relationship between the tert-butyl and epoxide entity (Figure 4). ${ }^{10}$

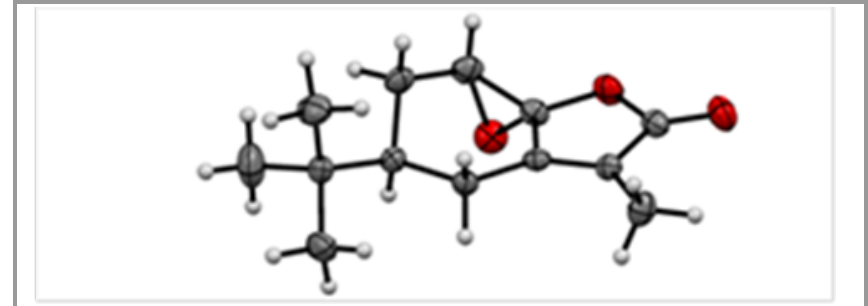

Figure 4 ORTEP representation of compound 16 with thermal ellipsoids at $50 \%$ probability.

The X-ray crystal structure of $\mathbf{1 7}$ (Figure 5) showed the hydroxyl groups of the diol were in trans-diaxial arrangement ${ }^{9}$ which suggested that the ring opening of epoxide $\mathbf{1 6}$ occurred according to the Fürst-Plattner rule. ${ }^{14}$

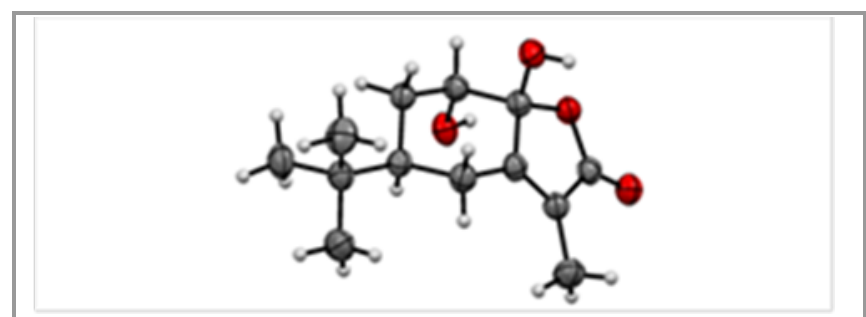

Figure 5 ORTEP representation of compound 17 with thermal ellipsoids at $50 \%$ probability.

Having gathered sufficient information on the chemical modifications of model compound 11, we then attempted similar transformations using rac-epi-lindenene (7) as starting material. Deprotonation of $\mathbf{7}$ with $n$-butyllithium and quenching the resultant anion with chlorotrimethysilane delivered $\mathbf{1 8}$ which was oxidised by singlet oxygen to epi-chloranthalactone D (19). It should be noted that this reaction was selective and no allylic oxidation of the exocyclic olefin was observed. Surprisingly, attempts to streamline the synthesis by subjecting epi-lindenene (7) to Clive's one step oxidation reaction that successfully oxidised the model compound $\mathbf{1 1}$ instead yielded compound $\mathbf{2 0}$ in moderate yield in which the migration of the double bond to the endocyclic position was observed despite the presence of monopotassium phosphate as buffer (Scheme 6). 


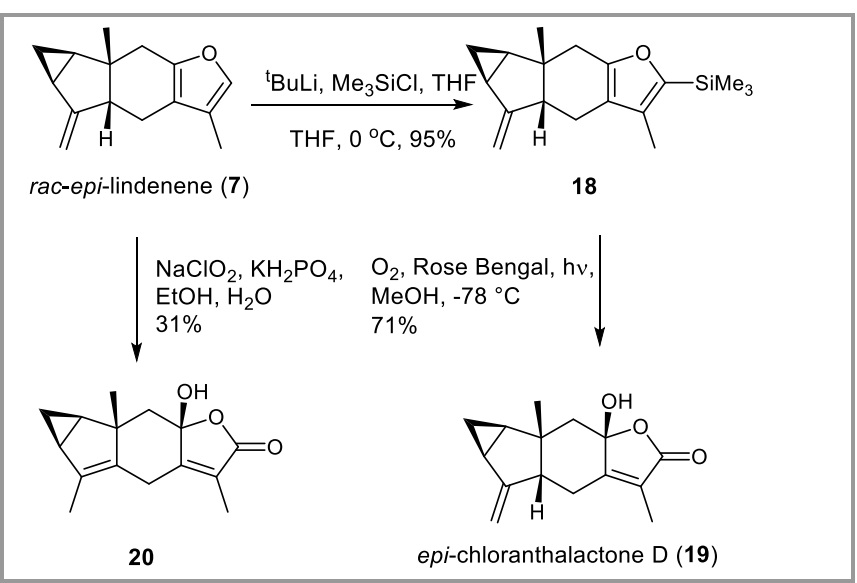

Scheme 6 Chemical modification of rac-epi-lindenene (7).

Compound 19 was then dehydrated with phosphoryl chloride ${ }^{1}$ and pyridine to epi-chloranthalactone A (21) which was converted to epi-chloranthalactone B (22), using $m \mathrm{mCBA}$ without affecting the exocyclic double bond. Ring opening of $\mathbf{2 2}$ with a catalytic amount of sulphuric acid delivered epichloranthalactone E (23) as product (Scheme 7).

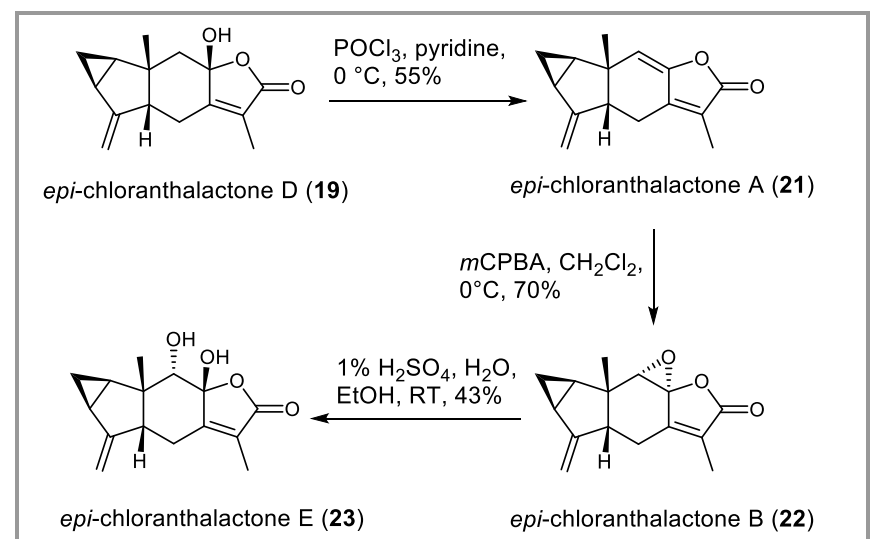

Scheme 7 Chemical modifications of epi-chloranthalactone $D(19)$ to the other epi-chloranthalactone derivatives.

In summary we have investigated various methods for the oxidative conversion of the furan ring to hydroxyfuranone, a moiety that is found in the natural product chloranthalactone $\mathrm{D}$ (4). By using epi-lindenene (7) as starting material, epichloranthalactone D (19) was successfully synthesised via singlet oxygen oxidation. This compound was found to be a versatile precursor for the synthesis of epi-chloranthalactones A, B, D and E. We believe that this route will provide an expeditious approach towards the synthesis of the natural chloranthalactones.

\section{Funding Information}

Click here to insert sources of funding, grant numbers, etc. Do not repeat the same in the acknowledgment.

\section{Acknowledgment}

Click here to insert acknowledgment text. Funding sources and grant numbers should be given above in the Funding Information section.

\section{Supporting Information}

YES (this text will be updated with links prior to publication)

\section{Primary Data}

NO (this text will be deleted prior to publication)

\section{References and Notes}

(1) Uchida, M; Koike, Y.; Kusano, G.; Kondo, Y.; Nozoe, S.; Kabuto, C.; Takemoto, T. Chem. Pharm. Bull. 1980, 28, 92.

(2) Kawabata, J.; Fukushi, Y.; Tahara, S.; Mizutani, J. Phytochemistry 1990, 29, 2332.

(3) Zhang, W.; Guo, Y.-W.; Mollo, E.; Cimino, G. Chin. J. Nat. Med. 2005, 3, 280-283.

(4) (a) Fenlon, T. W.; Schwaebisch, D.; Mayweg, A. V. W.; Lee, V.; Adlington, R. M.; Baldwin, J. E. Synlett 2007, 2679. (b) Liu, Y.; Nan, F.-J. Tetrahedron Lett. 2010, 51, 1374. (c) Yue, G.; Yang, L.; Yuan, C.; Jiang, X.; Liu, B. Org. Lett. 2011, 13, 5406. (d) Zhang, H.; Nan, F. Chin. J. Chem. 2013, 31, 84. (e) Qian, S.; Zhao, G. Chem. Comm. 2012, 48, 3530. (f) Yue, G.; Yang, L.; Yuan, C.; Du, B.; Liu, B. Tetrahedron 2012, 68, 9624. (g) Yuan, C.; Du, B.; Yang, L.; Liu, B. J. Am. Chem. Soc. 2013, 135, 9291. (h) Qian, S.; Zhao, G. Tetrahedron 2013, 69, 11169. (i) Yue, G.; Yang, L.; Yuan, C.; Lu, B.; Liu, B. Chin. J. Org. Chem. 2013, 33, 90. (j) Yang, L.; Yue, G.; Yuan, C.; Du, B.; Deng, H.; Liu, B. Synlett 2014, 25, 2471. (h) Yuan, C.; Du, B.; Deng, H.; Man, Y.; Liu, B. Angew. Chem. Int. Ed. 2017, 56, 637.

(5) Fenlon, T. W.; Jones, M. W.; Adlington, R. M.; Lee, V. Org. Biomol. Chem. 2013, 11, 8026.

(6) Kawabata, J.; Fukushi, Y.; Tahara, S.; Mizutani, J. Phytochemistry 1990, 29, 2332.

(7) (a) Corey, E. J.; Roberts, B. E. J. Am. Chem. Soc. 1997, 119, 12425. (b) Meng, D. F.; Tan, Q.; Danishefsky, S. J. Angew. Chem. Int. Ed. 1999, 38, 3197. (c) Margaros, I.; Montagnon, T.; Tofi, M.; Pavlavkos, E.; Vassilikogiannakis, G. Tetrahedron 2006, 62, 5308. (d) Ghogare, A. A.; Greer, A. Chem. Rev. 2016, 116, 9994.

(8) (a) Hagiwara, H.; Uda, H. J. Chem. Soc., Perkin Trans. 1 1984, 91. (b) Honan, M. C. Tetrahedron Lett. 1985, 26, 6393.

(9) (a) Kernan, M. R.; Faulkner, D. J. J. Org. Chem. 1988, 53, 2773. (b) Hagiwara, H.; Inome, K.; Uda, H. J. Chem. Soc., Perkin Trans. 1 1995, 757.

(10) The X-ray crystallographic data has been deposited with the Cambridge Crystallographic Data Centre (CCDC 1587570 (14), 1587571 (16) and 1587572 (17)). These files can be obtained free of charge from the Cambridge Crystallographic Data Centre via www.ccdc.cam.ac.uk/dat_request/cif.

(11) (a) Lee, G. C. M.; Syage, E. T.; Harcourt, D. A.; Holmes, J. M.; Garst, M. E. J. Org. Chem. 1991, 56, 7007. (b) Shiraki, R.; Sumino, A.; Tadano, K.; Ogawa, S. J. Org. Chem. 1996, 61, 2845. (c) Adam, W.; Rodriguez, A. Tetrahedron Lett. 1981,22, 3505.

(12) To a stirred solution of silylfuran 15 (362 mg, $1.53 \mathrm{mmol})$ in $\mathrm{MeOH}$ $(50 \mathrm{~mL})$ and THF $(10 \mathrm{~mL})$ was added Rose Bengal $(10 \mathrm{mg})$, and the mixture was cooled to $-78^{\circ} \mathrm{C}$. A steady stream of $\mathrm{O}_{2(\mathrm{~g})}$ was bubbled through the solution, and the reaction was irradiated with two $150 \mathrm{~W}$ tungsten lamps for $2 \mathrm{~h}$, after which the lamps were removed and the flow of $\mathrm{O}_{2}$ ceased. The reaction mixture was warmed to RT and the solvents removed in vacuo to yield a crude pink coloured residue, which was purified by flash chromatography (P.E. 30-40:Et ${ }_{2} \mathrm{O}, 1: 1$ ) to furnish hydroxybutenolide 12 (326mg, 95\%). m.p. $142-143^{\circ} \mathrm{C}$; $\mathrm{R}_{\mathrm{f}} 0.15$

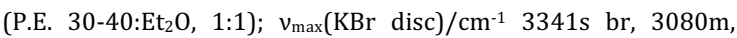
2931s, 2861s, 1740s, 1699s, $1430 \mathrm{~m}, 1121 \mathrm{~s}, 890 \mathrm{~m} ; \delta_{\mathrm{H}}(400 \mathrm{MHz}$, $\left.\mathrm{CDCl}_{3}\right) 0.96\left(9 \mathrm{H}, \mathrm{s},{ }^{\mathrm{t}} \mathrm{Bu}\right), 1.22(1 \mathrm{H}, \mathrm{app} \mathrm{t}, \mathrm{J}=7.0 \mathrm{~Hz}, 5-\mathrm{CH}), 1.49-1.59$ $(2 \mathrm{H}, \mathrm{m}, 6-\mathrm{CH}, 7-\mathrm{CH}), 1.81\left(3 \mathrm{H}, \mathrm{s}, 3-\mathrm{C}-\mathrm{CH}_{3}\right), 1.86(1 \mathrm{H}, \mathrm{m}, 6-\mathrm{CH})$, 
$2.09(1 \mathrm{H}, \mathrm{dt}, \mathrm{J}=12.5 \mathrm{~Hz}, 1.5 \mathrm{~Hz}, 4-\mathrm{CH}), 2.42(1 \mathrm{H}, \mathrm{dd}, \mathrm{J}=3.0 \mathrm{~Hz}$ $10.0 \mathrm{~Hz}, 7-\mathrm{CH}), 2.74(1 \mathrm{H}, \mathrm{dm}, \mathrm{J}=13.0 \mathrm{~Hz}, 4-\mathrm{CH}), 3.20(1 \mathrm{H}, \mathrm{br} \mathrm{s}, \mathrm{OH})$; $\delta \mathrm{c}\left(100.6 \mathrm{MHz}, \mathrm{CDCl}_{3}\right) 8.1\left(3-\mathrm{C}-\mathrm{CH}_{3}\right), 23.3(6-\mathrm{C}), 26.2(4-\mathrm{C}), 27.5$ $\left(\mathrm{RC}\left(\mathrm{CH}_{3}\right)_{3}\right), 32.8\left(\mathrm{RC}\left(\mathrm{CH}_{3}\right)_{3}\right), 37.7$ (7-C), 49.7 (5-C), $103.2(7 \mathrm{a}-\mathrm{C})$, 121.4 (3-C), 161.4 (3a-C), 173.2 (2-C); m/z (ES)- 223.26 [(M-H)-, $100 \%]$.

(13) (a) Clive, D. L. J.; Minaruzzaman; Ou, L. J. Org. Chem. 2005, 70, 3318. (b) Annangudi, S. P.; Sun, M.; Salomon, R. G. Synlett 2005
1468. (c) Pepper, H. P.; Lam, H. C.; George, J. H. Org. Bimol. Chem. 2017, 15, 4811.

(14) Fürst, A.; Plattner, P. A. Helv. Chim. Acta 1949, 32, 275. 